\title{
Benefit segmentation of a summer destination in Uruguay: a clustering and classification approach
}

\author{
Gonzalo Perera
}

Centro Universitario Regional Este, Universidad de la República, Rocha, Uruguay

Martin Sprechmann

Facultad de Ciencias Económicas y de Administración, Universidad de la República, Montevideo, Uruguay, and

Mathias Bourel

Facultad de Ingeniería, Instituto de Matemática y Estadística Prof. Rafael Laguardia, Universidad de la República, Montevideo, Uruguay

\begin{abstract}
Purpose - This study aims to perform a benefit segmentation and then a classification of visitors that travel to the Rocha Department in Uruguay from the capital city of Montevideo during the summer months.

Design/methodology/approach - A convenience sample was obtained with an online survey. A total of 290 cases were usable for subsequent data analysis. The following statistical techniques were used: hierarchical cluster analysis, K-means cluster analysis, machine learning, support vector machines, random forest and logistic regression.

Findings - Visitors that travel to the Rocha Department from Montevideo can be classified into four distinct clusters. Clusters are labelled as "entertainment seekers", "Rocha followers", "relax and activities seekers" and "active tourists". The support vector machine model achieved the best classification results.

Research limitations/implications - Implications for destination marketers who cater to young visitors are discussed. Destination marketers should determine an optimal level of resource allocation and destination management activities that compare both present costs and discounted potential future income of the different target markets. Surveying non-residents was not possible. Future work should sample tourists from abroad.

Originality/value - The combination of market segmentation of Rocha Department's visitors from the city of Montevideo and classification of sampled individuals training various machine learning classifiers would allow Rocha's destination marketers determine the belonging of an unsampled individual into one of the already obtained four clusters, enhancing marketing promotion for targeted offers.
\end{abstract}

Keywords Destination marketing, Benefit segmentation, Tourist typology, Machine learning

Paper type Research paper

(C) Gonzalo Perera, Martin Sprechmann and Mathias Bourel. Published in Journal of Tourism Analysis: Revista de Análisis Turistico. Published by Emerald Publishing Limited. This article is published under the Creative Commons Attribution (CC BY 4.0) licence. Anyone may reproduce, distribute, translate and create derivative works of this article (for both commercial and noncommercial purposes), subject to full attribution to the original publication and authors. The full terms of this licence may be seen at http://creativecommons.org/licences/by/4.0/legalcode

Received 25 July 2018 Revised 20 February 2019 Accepted 17 February 2020

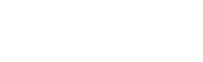




\section{Introduction}

For the past 15 years, Uruguay has experienced a prolonged expansion both in international arrivals and in tourism's share of gross domestic product (MINTUR, 2016). Tourism demand in Uruguay is driven in part by international arrivals, especially from Argentina, and by domestic tourism. Uruguay's tourism sector is also very exposed to external shocks - global and regional ones - and exhibits strong seasonality (Brida et al,, 2017). Besides, Uruguay has a long-standing tradition of second-home ownership that started as early as the 1950s and 1960s. Various destinations in Uruguay such as Punta del Este have experienced construction booms, and Rocha Department is no exception to this phenomenon. Residents of Uruguay and Argentina treat investments in real estate as assets that hedge against financial and currency crises.

Rocha Department is an administrative region in Uruguay located in the southeast of the country. It has a polycentric structure with many coastal towns along its $170 \mathrm{~km}$ of Atlantic coast, most notably Cabo Polonio. It has an area of $10,551 \mathrm{~km}^{2}$ and a population of approximately 70,000 inhabitants. Rocha Department has a relatively pristine environment that features beaches, coastal towns, sand dunes, historical sites, palm forests, wetlands and natural reserves. Rocha depends heavily on tourism arrivals and receipts during the summer months. Rice production and processing and beef cattle farming also contribute to Rocha Department's economy. Tourism development in Rocha Department has historically lagged other Uruguayan regions. Sun and beach tourism is by far the most sought-after product, followed by shopping in the city of Chuy near the border with Brazil and visitation to historical sites such as Santa Teresa Fortress and its many lighthouses. Other more sophisticated products have not yet been developed properly. Nonetheless, Rocha has a highly natural environment that reflects in its landscapes, beaches, lakes and sights.

Tourism arrivals in Rocha are highly seasonal, and this phenomenon has been the case ever since the first tourists arrived. The last complete data available show that during the first quarter of 2012, 256,513 residents visited Rocha Department (MINTUR, 2014a). Arrivals fell sharply in the three remaining quarters. Domestic arrivals sank to 66,666, 62,728 and 71,378 in the second, third and fourth quarters of 2012, respectively (MINTUR, 2014a). The trend for international tourists follows a similar pattern. A total of 79,637 international visitors stayed in Rocha during the first quarter of 2014 (MINTUR, 2014b). Data for the third quarter of 2014 show a tenfold reduction in non-resident arrivals, down to only 8,806 tourists (MINTUR, 2014b). The data reflects that i) domestic tourism is a key market for Rocha, representing approximately three quarters of total visitors, and ii) that seasonality is a major constraint. Additionally, Montevideo Metro Area accounts approximately for half the population of Uruguay.

These drought-deluge cycles diminish profitability, thus preventing small and microbusinesses from saving and investing, which is self-reinforcing (Punzo and Narbondo, 2009; Weaver, 2006). Most of the tourism development consisted of investments in second homes, which are used during short periods of the year (Punzo and Narbondo, 2009).

Sarigöllü and Huang (2005) carried out a market segmentation of visitors to Latin America that provides a comprehensive characterization of tourists that visit the whole continent. The authors call for further country-specific market segmentations in the Americas to complete a microlevel assessment of travel markets (Sarigöllü and Huang, 2005). Some authors have echoed this, working under the framework of segmenting specific destinations in Latin America (López-Guzmán et al., 2017; Niefer, 2005; Valdez et al., 2008). However, segmentation of Latin American destinations is relatively rare. Yet, performing a 
destination segmentation of Rocha Department is helpful for destination marketers to target and reach visitors more effectively and efficiently. An interesting question to address is how to develop a recommendation model for a new unsampled tourist that visits Rocha based on machine learning methods. To the best of the authors' knowledge, very few studies use of machine learning techniques as part of tourism market segmentation. For instance, Dutta et al. (2017) segment and classify domestic Indian tourists using a host of machine learning algorithms.

The contributions of this paper are twofold. First, regarding the above-mentioned call for microlevel characterization of Latin travel markets, a segmentation of visitors that travel to Rocha from Montevideo Metro Area during the summer months is carried out. Second, after performing the clustering algorithm for segmentation purposes, we use three supervised machine learning classifiers [logistic regression (LR), random forest (RF) and support vector machines (SVMs)] to see which technique obtains the best classifying results. This would allow classifying an unsampled individual into one of the clusters obtained previously.

Thus, the purpose of this study is to segment visitors that travel to Rocha from Montevideo Metro Area during the summer months according to benefits sought and classify them using three supervised machine learning techniques.

To perform this market segmentation and classification problem the following steps are necessary:

i) summarize benefits sought in a handful of factors to facilitate travel explanation and to conduct a dimensionality reduction;

ii) group tourists into homogeneous segments of visitors using cluster analysis;

iii) profile segments according to sociodemographics, travel behaviour variables and daily individual expenditure in Rocha Department; and

iv) develop and train various machine learning classifiers to predict cluster membership of a new individual not included in the original sample.

\section{Literature review}

\subsection{Market segmentation}

Market segmentation is the process of dividing heterogeneous consumers into smaller homogeneous customer groups (Kotler and Armstrong, 2010; Dolnicar, 2008; Peter and Donnelly, 2008). Any of these subsets can be conceivably selected as a market segment to be reached with a tailored marketing program. The concept of market segmentation was first introduced by Smith (1956) and Tynan and Drayton (1987). The three traditional, most commonly used segmentation strategies are mass marketing, differentiated marketing and targeted marketing (Kotler and Armstrong, 2010). With the emergence of big data in recent years, a much more complex segmentation method has arisen, known as "one-to-one marketing" (Mayer-Schönberger and Cukier, 2013).

The importance of segmentation research in tourism has been widely acknowledged, while conclusions translate into successful ways of developing destination marketing, targeting and positioning (Loker and Perdue, 1992; Sarigöllü and Huang, 2005; Tkaczynski et al., 2010). Because tourism marketers do not fully control product development or differentiation, and destination marketers do rarely control product operation, market segmentation in tourism has important strategic implications for selecting target segments (Li et al., 2013; Tkaczynski, 2009). Segmentation at the destination level is particularly challenging because different destinations are characterized by distinct features, diverse 
external factors and different past marketing programs (Rondan-Cataluña and Rosa-Díaz, 2014). Another key issue with regard to the effectiveness and robustness of the segmentation technique relates to the appropriate number of clusters derived (Almeida $e$ t al., 2014). Finally, some segments and specific publics are more relevant than others to the wellbeing of destinations and account for large portions of arrivals and total expenditure (Almeida et al., 2014).

Market segmentation can be either a priori or post hoc. In a priori segmentation, segments are delineated according to previously defined criteria, using one or more bases in combination (Dolnicar, 2004). The limitation of this approach lies in its inability to derive reliable market groupings (Tan and Lo, 2008). In contrast, in post hoc segmentation, consumers are grouped into segments as a result of data-driven research findings (Peter and Donnelly, 2008). This is done by assessing the similarity and dissimilarity of responses to a set of predefined measurable characteristics (Neal, 2005). A segment must be measurable, substantial and accessible for an organization to cater to its members (Kotler and Armstrong, 2010).

\subsection{Market segmentation of tourism destinations}

Destination segmentation is a well-established field of research in tourism management and destination marketing. Studies vary across four different types of vectors: territory or destination (country, region, city, town, area, etc.), bases used for segmentation (geographic, sociodemographic, psychographic and benefits), tourism typology (rural tourism, cultural tourism, ecotourism, etc.) and statistical techniques used. There are different commonly used bases to segment a destination market that can be used in combination: geographic, demographic, psychographic and benefit segmentation (Kotler and Armstrong, 2010; Laesser and Zehrer, 2012; Prayag, 2010; Tkaczynski et al., 2010). First, effective and straightforward, geographic segmentation base is the simplest way to segment a destination because all the marketing spending is concentrated in a particular location of potential visitors (Kotler and Armstrong, 2010). It is commonly used by destination marketing organizations at the national, regional and local levels (Kotler and Armstrong, 2010; Neuts et al., 2016; Pike, 2012). However, according to Kotler and Armstrong (2010), targeting tourists only according to where they live will most likely miss the heterogeneity of individuals and fall into mass marketing. Second, demographic segmentation assumes that interest for and visitation to a particular destination is correlated with variables such as age, gender, income level, spending level, family size and family life cycle (Collado et al., 2007; Kotler and Armstrong, 2010). These variables appear commonly as secondary data in reports published by public organizations or research firms. If collected as primary data of its own, respondents can answer relatively easy about these variables in a survey. Third, psychographic segmentation base divides consumers according to lifestyle, attitudes, interests, values and opinions (Peter and Donnelly, 2008). Tkaczynski (2009) states that psychographic segmentation has helped tourism marketers understand tourists' thoughts and attitudes, and tourists today prefer to describe themselves according to lifestyle and interests rather than other variables such as age or gender.

Finally, benefit segmentation relies on the fact that the benefits individuals seek from specific goods and services are the basic reason for the existence of true market segments (Haley, 1968). Benefit segmentation is considered more robust than other segmentation bases for predicting buying behaviour, whereas, for instance, geographic and sociodemographic descriptors are considered poor predictors (Haley, 1968; Rondan-Cataluña and Rosa-Díaz, 2014; Tan and Lo, 2008). The method has proven to be effective in 
segmenting markets in the tourism industry (Loker and Perdue, 1992; Sarigöllü and Huang, 2005).

In the realm of tourism destinations, segments of tourists have to be sufficiently heterogeneous in relation to each other, and segments also need to be valuable to the stakeholders of the destination, including residents. (Neuts et al., 2016). Kotler et al. (1993) divide visitors into three groups. The first group consists of those visitors who are worth attracting to the destination (Kotler et al., 1993). This first group may be the backbone of the local economy of the destination and have a behaviour and profile that fits the destination well. The second group is composed of individuals who may be worth attracting but are not necessarily vital to the destination (Kotler et al., 1993). Finally, some segments may be valuable for a handful of stakeholders but may also impose negative externalities on the rest of the residents or other visitors, and they may have to be discouraged to visit the destination (Kotler et al., 1993).

\subsection{Similar studies in South America}

Regarding segmentations in South America, the most important antecedent is a study that explores motivational dimensions among foreign visitors in the world heritage city of Quito, Ecuador (López-Guzmán et al., 2017). The authors found three relevant motivational decisions - i.e. factors for these visitors - cultural decisions, circumstance decisions and hedonism-gastronomic decisions (López-Guzmán et al., 2017). Subsequently, four clusters of tourists were derived. The following were labelled as "hedonic-gastronomic cultural tourist", "hedonic-gastronomic tourist", "circumstantial hedonic-gastronomic cultural tourist" and "alternative tourist" (López-Guzmán et al., 2017). One of the main contributions is that the degree of satisfaction of a Quito visit is conditioned by diverse motivations.

Niefer (2005) performed a benefit segmentation of visitors to "Parque Nacional de Superagüi” in the southern state of Paraná, Brazil. The author identified five distinct clusters: indifferents, nonsociable adventurers, sociable adventurers, enthusiasts and nonsociable enthusiasts. The methods consist of factor analysis - principal component analysis, in particular - followed by K-means cluster analysis to identify the groups of visitors. Niefer (2005) acknowledges that visitors to "Parque Nacional de Superagüi” belong to a wider segment of nature and ecotourism tourists.

Valdez et al. (2008) segment the visitors of San Martín de los Andes, Argentina. Located in the Argentinian Patagonia near the Andes, San Martín de los Andes is one of the most important mountain destinations in Argentina and South America. Valdez et al. (2008) identify six segments of visitors to the city using automatic interaction detection, a type of decision tree technique. The results enable the assessment of the attractiveness of each segment in terms of expenditure in the area.

Although the cruise ship literature is a separate branch of tourism research, it is worth mentioning as an example that Brida et al. (2014) applied classification and regression tree analysis (CART) to a sample of 5,151 cruise passengers in two ports of call in Uruguay specifically Montevideo and Punta del Este. The data corresponds to the 2008-2009 and the 2009-2010 cruise seasons. Passengers were first grouped into homogeneous groups of passengers using hierarchical cluster analysis. Afterwards, CART was used to determine which variables better-predicted cluster membership, thus using a machine learning method.

\subsection{Overview of machine learning and the logistic regression, support vector machines and random forest techniques}

Generally speaking, supervised learning consists to consider a dataset $L=\left\{\left(x_{1}, y_{1}\right),\left(x_{2}, y_{2}\right), \ldots\right.$, $\left.\left(x_{n}, y_{n}\right)\right\}$ where each observation $(x, y)$ contains a vector of variables $x$ (the imput vector) and 
belongs to $X$, a subset of $R^{p}$, and $y$ (the output) belongs to a set $Y=\{1, \ldots, C\}$, which is categorical (the response variable). More precisely, each coordinate of $x$ represents the value taken by a real random multivariate variable $X$, where each component is a real random variable and the output $y$ is the value taken by another real random variable $Y$ that takes value in a set of possible classes $1, \ldots, C$. The problem consists of using dataset $L$ to find a classifier $f: X \rightarrow Y$ to predict the value $f\left(x_{\text {new }}\right)=y_{\text {new }}$ of a new observation $x_{\text {new }}$ of $X$. A natural and very simple classification rule to do this, is to assign to an observation $x$ to the class computed by the classifier that maximizes the posterior probability that observation $x$ belongs to class $c$. Indeed, we have $C$ possible classes, and we could look at the $C$ posterior probabilities. Then we select the class with the highest probability and assign observation $x$ to this class. This classifier is known as the Bayes classifier. It minimizes the probability of being wrong (Devroye et al., 1997). But for empirical data, it is impossible to compute the Bayes classifier, because the true distribution of the vector $(X, Y)$ is unknown, so the objective of statistical modelling is to obtain an estimator to approach this classifier given the available data. We refer the interested reader to the specialized literature for further details (Vapnik, 1995; Devroye et al., 1997; Hastie and Tibshirani, 2013; James et al., 2013).

To have a good generalization performance on new data, the computed function cannot fit too much the data used to construct it. A way of doing this is splitting original data $L$ randomly in two parts: the first will serve to train the model and it is called the training (or learning) sample $L_{1}$, and the second $L_{2}$ is called the test sample and will evaluate the performance of the method. More precisely, the model is constructed using $L_{1}$ by finding a classifier $f$ that minimizes the error of misclassification over $L_{1}$ and it is evaluated using the difference between the predicted class and the observed class. That is, for each observation $\left(x_{1}, y_{1}\right)$ of the sample, we compute $f\left(x_{i}\right)$ and look if $f\left(x_{i}\right)=y_{i}$ or not. The generalization error is performed on $L_{2}$, the data not used to construct the model, and it is an honest estimation of the true error. To avoid the bias caused by the original random split, the partition of $L$ is done several times and the overall error is an average over the different test samples. The following paragraphs describe briefly each technique used in this study: multinomial logistic regression (MLR), SVM and RF.

2.4.1 Multinomial logistic regression. The generalized linear models (GLMs) extend the linear models to include error distributions other than Gaussian and categorical response variables (Nelder and Wedderburn, 1972). The general form of a GLM is very close to the traditional linear model linking through a linear combination the explicative variables of the problem and the response. The most known GLM is the LR, where the dependent variable is binary, 0 or 1, and use the logit function (James et al., 2013). The variable selection in LR can be performed using the Akaike information criterion (Akaike, 1981). LR can be adapted directly in a model with a variable response with more than two categories, using the MLR that combines the performance of several classifiers, assuming that the response variable has multinomial distribution. Knowing the LR respect to the base category $C$ provide us the logits for any pair of class, the posterior probability can be easily calculated and the classification rule is made assigning to $x$ the class of highest probability (Greene, 2012).

2.4.2 Support vector machines. This method was introduced by Vapnik (1995). The purpose is to find hyperplane that separates different groups of observations. It is done by maximizing the margin of separation of the data between the groups. An observation is classified according to the side of the hyperplane it belongs. Even if the data is not completely linearly separable or if it is actually impossible to find a hyperplane that separates it, SVM can map the observations in a space of higher dimension where it could be much simpler to separate them linearly (Hastie et al., 2008; James et al., 2013). This fact is based on the intuitive idea that it is easier to do a separation in a larger space (Vapnik, 1995; 
James et al., 2013). It is possible considering a cost-complexity parameter and using kernel methods, generally using the radial kernel. Once we find the linear separation, the discriminant curve between the groups in the original space is the projection of the discriminant hyperplane. In the multiclass context, the SVM generally uses the one-vs-one approach: for each pair of classes, the method finds a classifier to compare them. An observation is classified by these ensembles of classifiers and the final assignment is done by majority vote (choosing the class that most frequently appears).

2.4.3 Random Forest. CARTs were introduced by Breiman et al. (1984). Their principal advantage is that they provide a recursive binary partition of the data space with a direct interpretation that can be represented by a decision tree (Figure 1). This method was revolutionary at that time because it was one of the first non-parametric prediction methods, it is very simple to interpret, has great performance, and provides a way to obtain the importance of the different variables that are involved in the splits. However, one major drawback of CART is its instability, i.e. a small change in the training sample implies a big change in the tree structure and prediction outcome. As a way to stabilize such classifiers, ensemble methods, consist of constructing a large set of classifiers generated using the same data set and combining them, with the aim of performing the variance to generate a more stable and performer predictor (Hastie et al., 2008; Bourel, 2012; Bourel, 2013; James et al., 2013).

An example of them is RF (Breiman, 2001) that combines classification trees using two layers of randomness for constructing each tree of the forest. The algorithm begins by randomly choosing a sample of the original learning data with reposition. Then a tree is grown as in CART with the main difference: at each split of a node, the method selects a random subsample (much smaller) of the predictor variables. After $M$ trees are constructed, the aggregation is done by the majority vote of the predictions: that is, the selected class of a given observation is the one with most votes in each of the $M$ trees of the forest (Figure 2).

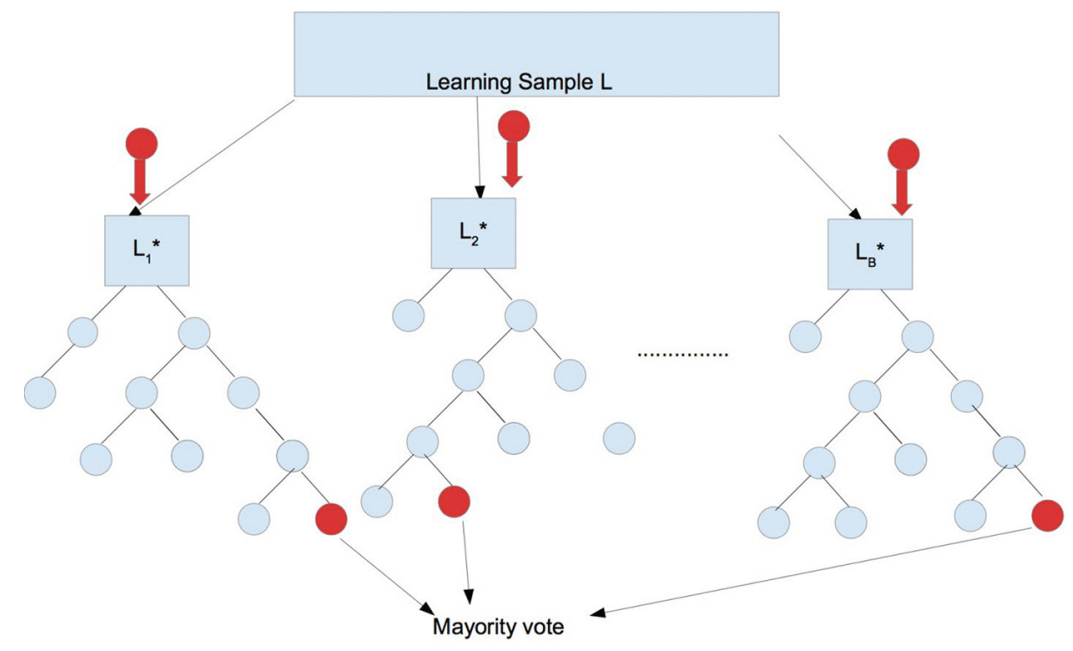

Notes: The prediction for a new observation is done as follows: the method looks at the prediction of the $M$ trees and then defines the label as the one selected more times, i.e. by majority vote
Benefit
segmentation

191
Figure 1.

$\mathrm{RF}$ constructs several trees, each of them built over a resample from the original dataset and at each split randomly selects a random subsample of the set of predictor variables and chooses the best split 
Figure 2.

Classification tree showing the repartition of the tourists in the four clusters

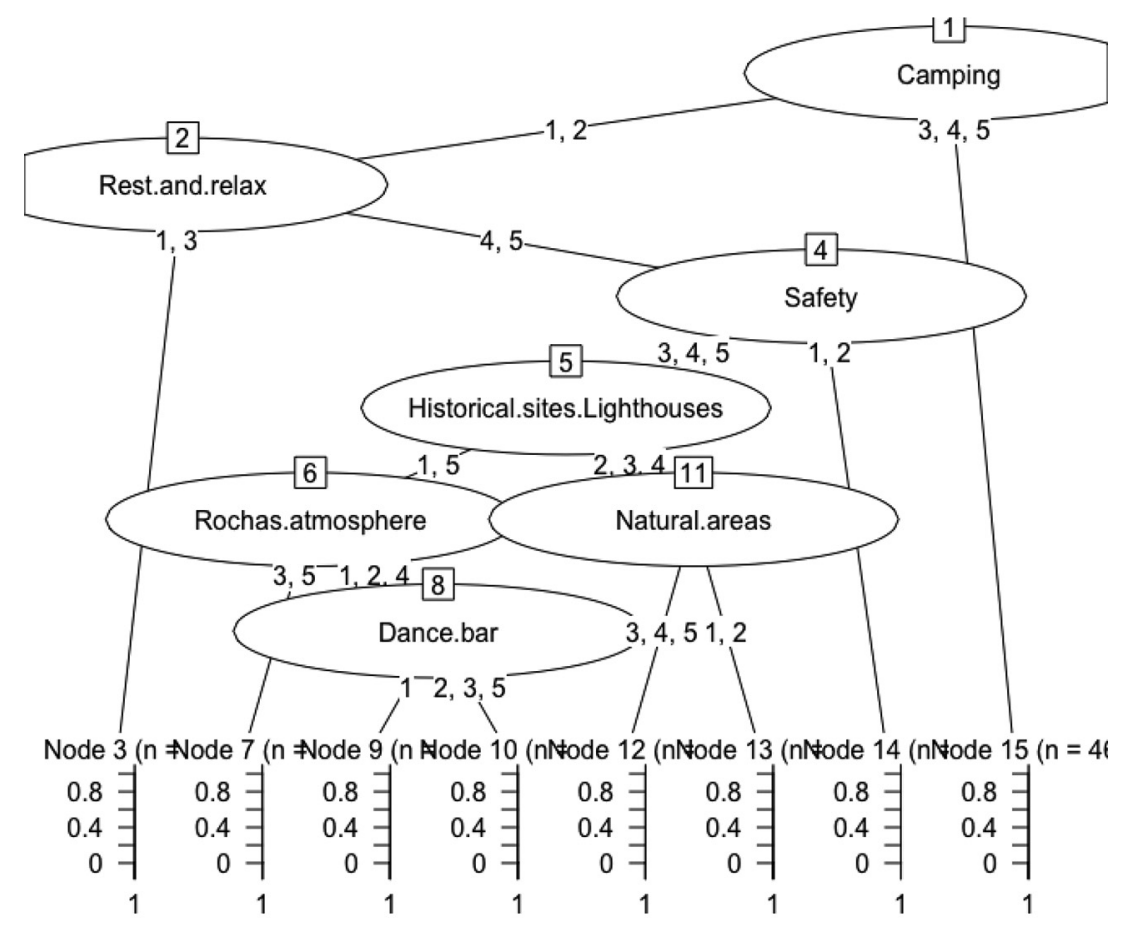

Notes: Numbers 1 to 4 in the terminal nodes represent cluster 1 to 4

$\mathrm{RF}$ is probably one of the most efficient learning algorithms in terms of prediction accuracy and it runs fast and efficiently over large data sets (James et al., 2013). Furthermore, it offers an approach to assess the importance of each explanatory variable used in the model. There are two ways of doing this. The first is called the mean decrease in the Gini coefficient and evaluates if a variable has an important contribution to splitting a node in two more homogeneous ones (Figure 3). The second is the mean decrease in accuracy based on a permutation of the variable: if the variable is not important, then randomly rearranging the values of it will not affect the prediction accuracy (Breiman, 2001).

\section{Methodology}

An online survey was conducted to collect data about tourists that travelled to Rocha Department during the summer and resided in Montevideo Metro Area. The data collection process resulted in 290 usable cases. The following paragraphs describe each step of the methodological framework: questionnaire development, data collection and data analysis.

\subsection{Questionnaire development}

The questionnaire design considered both the research objectives and a selection of prior relevant academic studies. Sue and Ritter (2012) state that online surveys' questionnaires must be developed according to some precise criteria. They have to be as short as possible. 


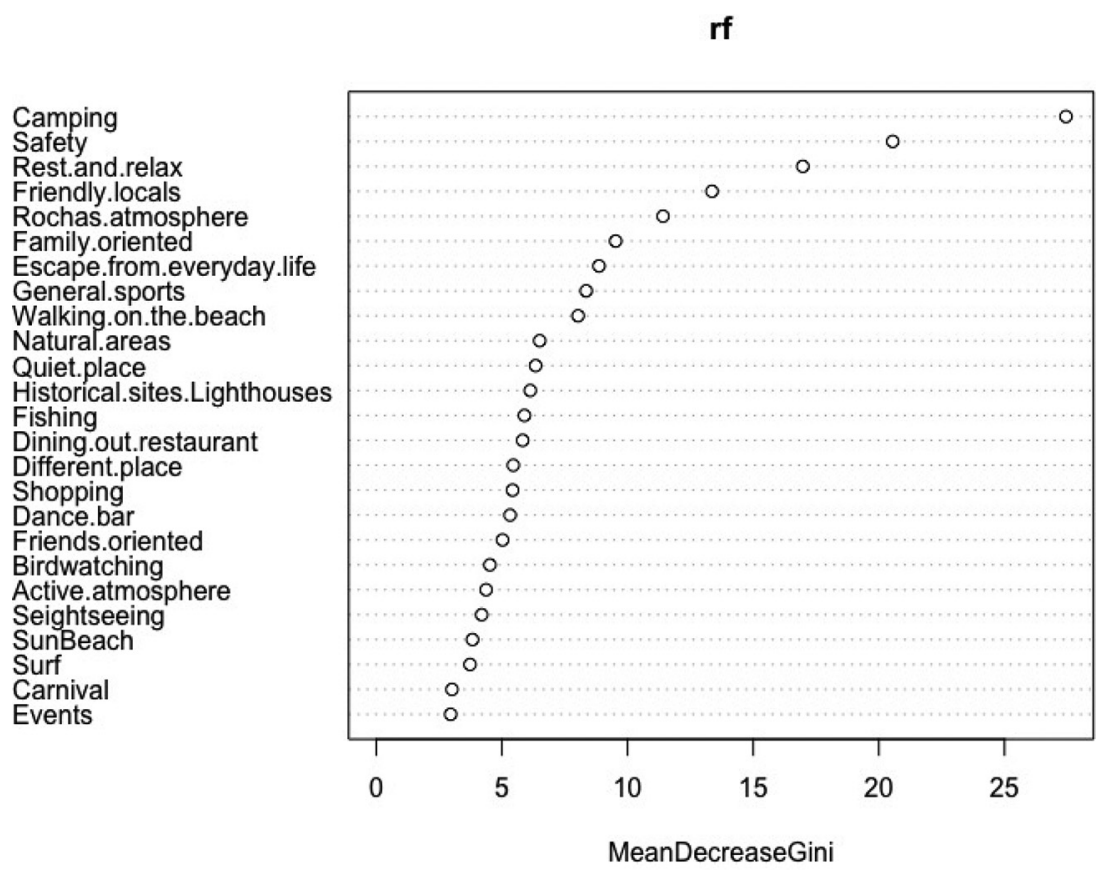

\section{Benefit segmentation}

193

Figure 3.

Importance of variables after performing the RF model

Therefore, researchers should include only the important questions that address research objectives. Long online surveys can be easily abandoned in the middle of the data entry (Sue and Ritter, 2012), resulting in large non-response rates. Nevertheless, online surveys possess advantages such as the speed, cost and possibility to reach a wider audience (Sue and Ritter, 2012).

The questionnaire included five sections. Section 1 explained the purpose of the online survey in four short paragraphs. Section 2 asked about the residence of the respondent and the destinations visited while on vacation during the summer of 2013. Those who spent at least one day in Rocha Department and resided in Montevideo Metro Area continued to the third section. In Section 3, respondents answered about a variety of travel behaviour variables such as main place of stay in Rocha Department, sources of information for trip planning, trip planning anticipation, type of accommodation, length of stay, transportation to the region and travel party composition (TPC). In addition, the questionnaire included questions about on-destination expenditure in accommodation, food and beverages, and shopping items. Four questions are similar to the questions asked by Tkaczynski (2009). Three expenditure questions and TPC were adapted from Tkaczynski (2009). Most questions were designed specifically for the study and discussed with a senior market researcher later on.

Special emphasis was put on the development of benefits statements. These are a crucial part of the questionnaire because responses to benefit statements are inputs of the principal component factor analysis and machine learning techniques. The 25 benefits statements were included in Section 4 of the questionnaire and appeared as a single page in the online form. A complete response to this question was compulsory to avoid missing cases. 
Statements were measured on a five-point Likert scale where 1 was "not important at all" and 5 was "very important". All 25 statements are listed in the Appendix.

Finally, Section 5 covered demographics as well as questions used to estimate the socalled "socioeconomic level" of respondents. This method is designed to overcome high nonresponse rates when specifically asking for the income of respondents in Uruguay (Llambí and Piñeyro, 2012). A pretest with 21 participants was carried out to fine-tune the questionnaire. A senior market researcher revised and made suggestions for preparing the final questionnaire.

\subsection{Data collection}

The online survey was conducted in June and July of 2013, after the summer months of that year. Respondents were selected using a snowball sampling procedure. The questionnaire was embedded in an online survey provider website. Participants were initially contacted via email and Facebook posts. The sampling frame for email respondents consisted of the contact lists of four email accounts. Email respondents received an invitation to participate in the survey and were asked to forward the mail to as many connections as possible. All initial participants were sent reminders 4- 5 days after the initial message. Additionally, a link to the survey was posted in three Facebook accounts and spontaneously shared by some connections.

The survey was completed by 612 respondents of which 290 cases were usable for the purpose of the study. The difference in the effective 290 observations of interest for the study and the 612 total responses stems from different types of respondents. Either these 322 respondents abandoned the questionnaire, did not live in Uruguay but filled a complete survey, resided in Uruguay but outside Montevideo Metro Area, or resided in Montevideo Metro Area but travelled to other parts of Uruguay, or travelled abroad, or could not leave their place of residence during the summer. In any case, all of these responses were disregarded prior to data analysis.

No sampling frame was available for conducting the survey. In these cases, nonprobabilistic techniques such as snowball sampling can overcome this limitation. This technique allows generating large sample sizes in a cost-effective way. It is important to note that no quotas were used, either by gender, age, education or by any other relevant variable. The procedure did not take quotas into account to use the full set of complete observations in subsequent data analyses.

\subsection{Data analysis}

3.3.1 Factor analysis and cluster analysis. Data analysis involved (a) conducting a factor analysis to summarize and reduce the 25 benefit statements to a handful of factors that explain travel behaviour in Rocha Department, and (b) grouping respondents with cluster analysis into homogeneous groups of benefits sought.

Up to this stage, the process is similar to many other segmentation studies (Johns and Gyimóthy, 2002; Loker and Perdue, 1992; Prayag, 2010; Sarigöllü and Huang, 2005; Tan and Lo, 2008). Part c of the analysis consisted of training various classifiers. Parts a and b were carried out using SPSS, version 19. Part c was performed using the R Program. First, factor analysis was performed with the 290 responses to the 25 statements of benefits sought. A standard varimax rotation was undertaken. Only factors with eigenvalues greater or equal to 1.0 were extracted. In step 1 of cluster analysis, hierarchical cluster analysis was used to identify a preliminary set of cluster solutions (Hair et al., 2010). With an appropriate "stopping rule", hierarchical cluster analysis allows identifying an adequate or optimal number of clusters 
according to previously specified criteria (Hair et al., 2010). In this particular hierarchical procedure, the algorithm chosen was Ward's method, whereas the similarity measure selected was the square Euclidean distance. The agglomeration schedule indicated that the largest proportional increase in the agglomeration coefficient occurred after combining four clusters and three clusters. Thus, these solutions were considered preliminary adequate. In step 2 of cluster analysis, the factormean scores for each respondent were used in three K-means clustering procedures. The 3-cluster, the 4-cluster, and the 5-cluster solutions were explored using K-means cluster analysis. The 4-cluster solution was considered more interpretable and insightful and therefore was selected as the final solution for the study. Also, the 4cluster solution most appropriately met the criteria of being measurable, substantial and actionable.

3.3.2 Classification. With the different groups obtained upon the clustering process explained above, a supervised classification was performed assigning a label to each cluster. Indeed, for each observation of our data basis, we get its different characteristics into a vector $\mathrm{x}$ (the answers to each question) and a label $\mathrm{y}$ (the cluster to which the observation belongs).

The three classification models used were MLR, SVMs and RF. These were trained using two-thirds of the sample as the training set and one-third of the sample as the test set. All programs used in the simulations were run with the statistical software R (R Core Team, 2016), using package mnlogit for MLR, package e1071 for SVM, package Random Forest for $\mathrm{RF}$, and package partykit for graphical visualization of CART. For SVM, we use a radial kernel and optimize the parameters with function tune.svm. For RF, 200 intermediate trees were used. The results represent misclassification error rates more than 100 independent runs of the different algorithms.

\section{Results and discussion}

\subsection{Factors of benefits sought}

Principal component factor analysis after varimax rotation unveiled seven factors of benefits sought by tourists from Montevideo in Rocha Department. Standard indicators such as the Kaiser-Meyer-Olkin measure of sampling adequacy (0.796) and Bartlett's test of sphericity rendered acceptable results for conducting principal components analysis. These factors explain 61.5 per cent of the total variance. Table I summarizes the results. Each factor shows the five variables with the highest loading in absolute terms except for Factor 7, "camping”. This Factor only has four variables. Factor 1 was labelled "entertainment". It includes a series of variables with high loadings related to nightlife but also comprises other activities that are sought by tourists with diverse lifestyles such as "dinning/restaurant" and "events". Factor 2 consists of four attributes that are specific to Rocha Department: "safety", "friendly locals", "family oriented" and "Rocha's atmosphere". These attributes pull tourists to this area in particular. Therefore, Factor 2 was labelled "characteristics of Rocha". Factor 3, named "relaxation", includes "push" activities such as "rest and relax", "escape from everyday life" and "sun/beach". Factor 4 "nature" includes "visiting natural reserves" and "sightseeing". Factor 5, labelled "sports", comprises "surf" and "fishing" and "general sports". Factor 6 consists of "shopping" and "visiting historic sites and lighthouses". Factor 7 has only a single variable with high loading, namely, "camping". Factors 1,6 and 7 comprise activities that are popular in Rocha. The "dance/bar" variable, which has the highest loading in factor 1 , reflects the presence of multiple clubs and nightlife-oriented towns such as La Pedrera and Punta del Diablo. The town of Chuy, near the border with Brazil, is almost 
JTA

27,2

196

\begin{tabular}{lcc}
\hline Factor extracted & 1 & 2 \\
\hline Factor 1: Entertainment & & \\
Dance/bar & 0.862 & \\
Active atmosphere & 0.820 & \\
Dining/restaurant & 0.646 & \\
Events & 0.643 & \\
Friends' oriented & 0.527 & \\
Factor 2: Characteristics of Rocha & & \\
Safety & & 0.785 \\
Friendly locals & 0.751 \\
Family-oriented & 0.688 \\
Rocha's atmosphere & 0.590 \\
Quiet place & & 0.398
\end{tabular}

Factor 3: Relaxation

Rest and relax

Escape from everyday life

Sun/beach

Quietness

Walking on the beach

3

$4 \quad 5$

6

7

Factor 4: Nature

Natural areas

Sightseeing

Walking on the beach

Birdwatching

Different place

Factor 5: Sports

Surf

Fishing

General sports

Events

Camping

0.785

0.751

0.688

0.398

0.788

0.764

0.690

0.556

0.516

Factor 6: Activities and tours

Shopping

Historic sites/lighthouses

Fishing

Birdwatching

Family-oriented

0.707

0.688

0.498

0.492

0.443

Factor 7: Camping

Camping

Table I.

Dining/restaurant

Factors extracted

Friends' oriented

after conducting

principal component

Birdwatching

Eigenvalue

$\%$ of variance

Total variance explained (\%)

5.06

20.23

61.54

\begin{tabular}{|c|c|c|c|c|c|c|}
\hline & & & & & $\begin{array}{l}0.792 \\
0.588 \\
0.447 \\
0.423 \\
0.335\end{array}$ & \\
\hline & & & & & & $\begin{array}{r}0.766 \\
-0.401 \\
0.344 \\
0.316\end{array}$ \\
\hline $\begin{array}{r}5.06 \\
20.23 \\
61.54\end{array}$ & $\begin{array}{r}3.15 \\
12.58\end{array}$ & $\begin{array}{l}2.13 \\
8.53\end{array}$ & $\begin{array}{l}1.50 \\
6.01\end{array}$ & $\begin{array}{l}1.43 \\
5.73\end{array}$ & $\begin{array}{l}1.11 \\
4.46\end{array}$ & $\begin{array}{l}1.00 \\
4.00\end{array}$ \\
\hline
\end{tabular}

exclusively oriented towards shopping. Factor 6 captures some of this pattern. Finally, camping (Factor 7) is a preferred accommodation option in Rocha because of its affordability. Parque Nacional Santa Teresa and the towns of La Paloma, Punta Rubia and Barra del Chuy possess camping sites. 

can be grouped into four distinct clusters using K-means cluster analysis. Segment 1, labelled "Entertainment seekers", comprises 12.1 per cent of total respondents and is thus the smallest segment $(n=35)$. Its members are interested in entertainment while having very little interest in relaxation. Entertainment seekers also attach value to some extent to camping. Segment 2, the "Rocha followers", is the biggest segment obtained $(n=108)$, and it represents 37.2 per cent of the overall sample. It is the only segment that values a series of attributes of Rocha included in Factor 2, "characteristics of Rocha”. Its members also travel to Rocha Department to rest and relax. Segment 3, labelled "relax and activities seekers", is also a relatively large segment $(n=98)$ that accounts for 33.8 per cent of the sample. Its members are interested in shopping and visiting historic sites in the region, while also enjoying relaxation. However, this segment has very little interest in Factor 2, "characteristics of Rocha”. Segment 4, the "active tourists", a small segment that comprises 16.9 per cent of respondents $(n=49)$, are interested in a variety of outdoor activities available in Rocha Department, such as camping, visiting natural areas, sightseeing, surfing, fishing and sports in general, in a relaxed and quiet setting.

Table II depicts the mean scores of clusters centres for the four segments. ANOVA results show that the mean scores of clusters centres across the four clusters differ the most in terms of Factor 3 "relaxation" $(F=115.360)$, followed by Factor 2 "characteristics of Rocha" ( $F=80.018)$. Conversely, mean scores of cluster centres are more similar with respect to Factor 1 "entertainment" ( $F=3.100)$, and Factor 4 "nature", $(F=5.939)$."

\subsection{Profiling of segments and marketing communications}

This section helps understand the profiles of each of the four segments. The most noticeable characteristics are provided in the following descriptions. "Entertainment seekers" are predominantly male and younger than the rest of the sample. This segment plans their trips with much less anticipation. "Entertainment seekers" are the only segment for which the most frequent TPC is groups of friends. Nearly one-third of members select the town of Punta del Diablo as their main place of stay in Rocha.

\begin{tabular}{lcccccc}
\hline & $\begin{array}{c}\text { Entertain-ment } \\
\text { seekers } \\
N=35\end{array}$ & $\begin{array}{c}\text { Rocha } \\
\text { followers } \\
N=108\end{array}$ & $\begin{array}{c}\text { Relax and activities } \\
\text { seekers } \\
N=98\end{array}$ & $\begin{array}{c}\text { Active } \\
\text { tourists } \\
N=49\end{array}$ & $\begin{array}{c}\text { ANOVA } \\
\text { results } \\
F\end{array}$ & $\begin{array}{c}\text { Significance } \\
p \text {-value }\end{array}$ \\
\hline & $12.1 \%$ & $37.2 \%$ & $33.8 \%$ & $16.9 \%$ & statistic & \\
Entertainment & 0.430 & -0.029 & -0.008 & -0.227 & 3.10 & 0.027 \\
Characterstics of & & & & & & \\
Rocha & -0.313 & 0.830 & -0.737 & -0.132 & 80.02 & 0.000 \\
Relaxation & -1.990 & 0.263 & 0.328 & 0.184 & 115.36 & 0.000 \\
Nature & -0.270 & -0.045 & -0.111 & 0.514 & 5.94 & 0.001 \\
Sports & -0.140 & -0.166 & -0.222 & 0.909 & 19.43 & 0.000 \\
Activities and & & & & & & \\
tours & -0.180 & -0.357 & 0.550 & -0.184 & 18.19 & 0.000 \\
Camping & 0.125 & -0.347 & -0.365 & 1.405 & 71.01 & 0.000
\end{tabular}

Notes: ${ }^{a}$ The mean difference is significant $(p<0.05)$ 
Meanwhile "Rocha followers" consist of a majority of women. Of ten members, four are aged between 30 and 39 years. This is the highest mark between segments for this age range. They stay for longer periods of time in Rocha during the summer in comparison to other segments. Also, the majority of "Rocha followers" travel with their families. This segment tends to stay at rented houses. Members stay predominantly at the towns of La Paloma, Cabo Polonio and La Pedrera.

"Relax and activities seekers" are relatively balanced between men and women. Its members tend to stay in Rocha for shorter periods of time than Rocha Followers. Tourists aged between 18 and 39 years comprise the bulk of this segment. Of ten members, two stay at owned second homes, a value that doubles the marks for the other segments. The most frequent TPC is "families". The main places of stay that "relax and activities" choose are located in the east of Rocha Department as well as the town of La Paloma.

Finally, the "active tourists" are comprised of more women and younger members. Approximately one-third of the "active tourists" stay at camping sites, which is consistent with the fact that they are very interested in Factor 7, "camping". This segment also travels by public bus to Rocha Department much more than the rest of the segments. Their preferred place of choice is Parque Nacional Santa Teresa.

It is interesting to look at profiling variables for the four clusters obtained. Table III provides insight into each segment profile. This table shows the four segments and the mode for each of the travel behaviour and expenditure variables included in the survey. Six variables show very little variation across segments, namely, income of respondents, sources of information for planning the trip to Rocha, transportation to Rocha, daily individual expenditure in accommodation, daily individual expenditure in food and beverages and daily individual expenditure in shopping items. The "socioeconomic index" ("Índice de Nivel Socioeconómico") of all respondents in the sample -as measured in Uruguay- is predominantly "high" (71.4 per cent). "Knowledge of the region" is by far the most relevant source of information for respondents as a whole (84.8 per cent), followed by recommendations of families and friends (24.1 per cent), and browsing the Internet (20.0 per cent).

\subsection{Classification results}

Table IV shows the different performances of the classifiers developed for this study. SVM rendered the best results, followed by RF. MLR exhibited the poorest classification capabilities for this problem. Besides, the SVM model also allows validating the K-means cluster solution. Additionally and on the basis of responses to the 25 benefit statements, the three models allow to classify the membership of a new individual in one of the four clusters. For an unsampled individual, each technique will have a certain associated probability with regard to its cluster membership. SVM is the best classifier in this setting, so using this algorithm will produce the best classification results.

\section{Conclusions and implications}

Tourists that travel to Rocha Department from Montevideo Metro Area can be effectively segmented according to benefits sought. The four segments obtained are "entertainment seekers", "Rocha followers", "relax and activities seekers", and "active tourists". Furthermore, principal component factor analysis uncovered seven factors of benefits sought by these tourists in Rocha Department during the summer.

To the best of the authors' knowledge, few segmentation studies have been conducted in South America at the destination level. This leaves many travel markets without a proper understanding and explanation of visitor behaviour. This study addresses this issue by 


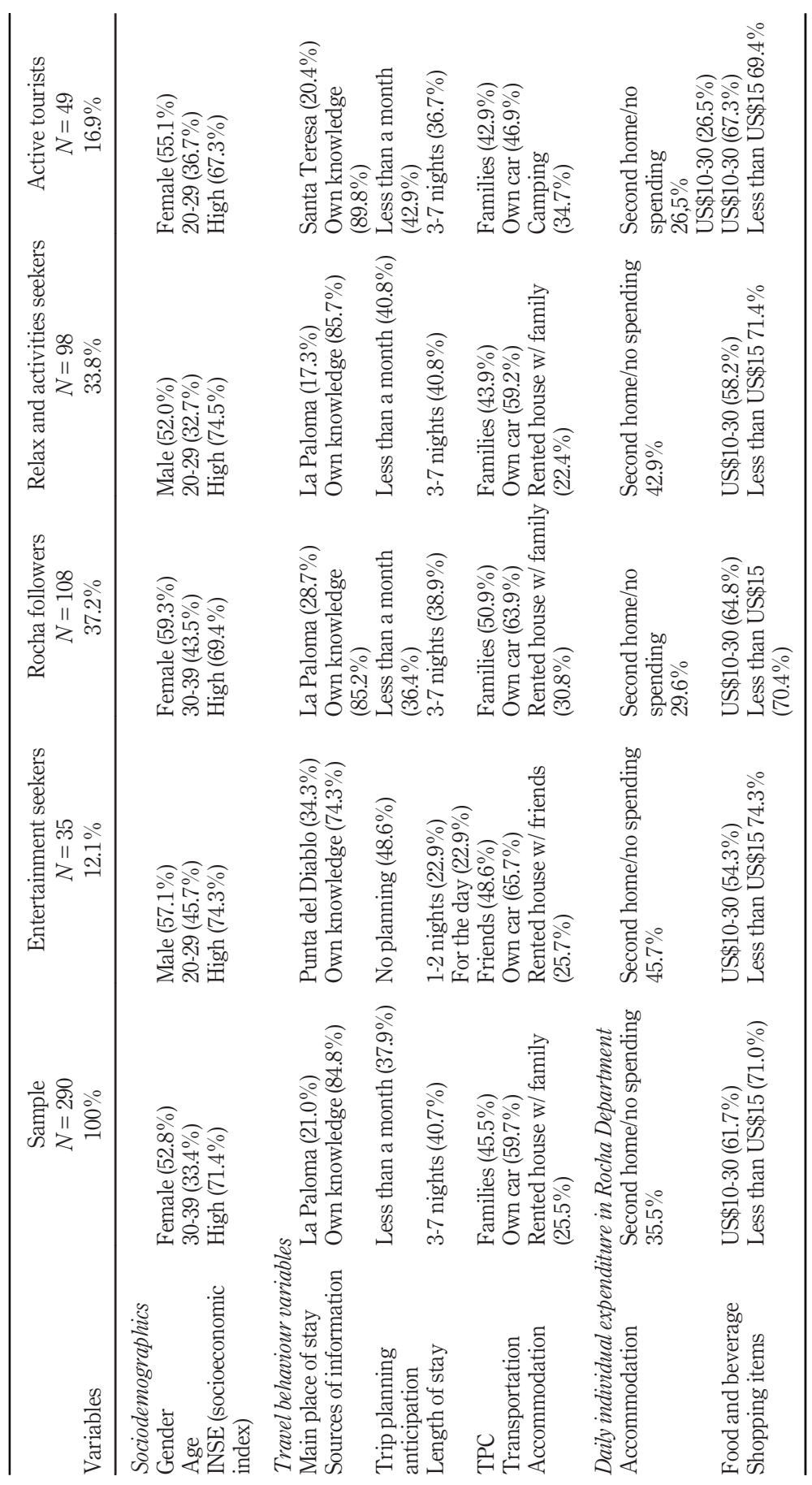

Table III.

Sociodemographic, travel behaviour and daily individual expenditure in Rocha for the sample and the four segments obtained 
JTA

27,2

200

providing a characterization of Rocha Department's visitors for its main source market, Montevideo Metro Area.

\subsection{Machine learning applications}

One of the main contributions of this study is the combination of a segmentation approach with a classification problem in order not only to obtain a taxonomy of the tourists but to test the classification accuracy of the derived segments with different machine learning models. It is important to note that, to the best of the authors' knowledge, the usage of machine learning models is still a very uncommon practice among segmentations studies in the field of tourism. This study classifies tourists using three machine learning models: support vector machines, RF, and multinomial LR. For the problem at hand, SVM was the most efficient classifier. This result is in line with its generally good capabilities in a variety of classification problems.

The most suitable use of the classification model developed, bearing in mind that SVM is the best classifier, is for destination marketing purposes. Rocha's destination marketers can determine the belonging of unsampled individuals to the four obtained clusters with a given probability. This can be used in subsequent promotional messages, were tourists are surveyed again - but importantly, only using the 25 benefits statements - in an online or offline questionnaire. By knowing the most likely membership to a cluster of a newly sampled individual, in light of the profiling made in this study, destination marketers could eventually target them according to their responses. For instance, a person likely to fall into the "active tourist" segment would be more responsive to fishing, surfing and sports activities' ads and offerings. Likewise, a person likely to fall into the "relax and activities seekers" segment would be more interested than likely members of other segments to shop in Rocha Department city of Chuy and its different craft fairs. Moreover, this methodology that consists of applying factor-cluster analysis and then classifying visitors can be used in any other destination - after adjusting benefits sought statements to the destination.

\subsection{Destination marketing recommendations for Rocha}

Both "Rocha followers" and "relax and activities seekers" constitute the largest segments of tourists from Montevideo Metro Area. Hence, these two segments should be given priority when allocating marketing expenditure. "Rocha's followers" are much more interested than the median respondent on Factor 2, "characteristics of Rocha". The segment is attracted towards Rocha specifically, so it is a segment worth continue targeting. It is important to note that "relax and activities seekers" are much less interested in Factor 2, "characteristics of Rocha", than the three remaining segments (Table II). Hence, Rocha's destination marketers should be aware that this might be a volatile segment that may flock elsewhere. Its main drivers of benefit sought are "relaxation" and "shopping", and the latter can be done in other places.

In contrast, the "active tourists" and the "entertainment seekers" comprise smaller groups of visitors. The benefits "active tourists" pursue are related to the outdoors. So, catering for this segment could be appropriate in terms of destination management strategy

Table IV.

Performance

comparison of

different machine

learning

classification models
Classifiers

Classification accuracy (deviation)

SVMs

$\mathrm{RF}$

MLR
$84.34 \%(0.039 \%)$

$78.54 \%(0.043 \%)$

$51.32 \%(0.062 \%)$ 
given that Rocha Department has plenty of natural resources. Conversely, it should be acknowledged that many of the benefits related to nightlife that "entertainment seekers" value, impose negative externalities on mainstream tourism. This is evident since the variable with the highest loading in Factor 1 is "dance/bar", while the second variable is an "active atmosphere". For instance, Kotler et al. (1993) cite a series of social costs of visitors. These costs include undesirable publics visiting the destination, damage to the environment, crowding and the rise of low-paying jobs (Kotler et al., 1993). Hence, the external cost "entertainment seekers" impose on the rest of the segments should be compared with their potential future income flows for the destination. In the setting of this study, the rather young "entertainment seekers" could eventually become "Rocha followers" or "relax and activities seekers" later in their lifetime. If treated too harshly, "entertainment seekers" could defect to other destinations outside Rocha Department, preventing this potential segment transition and reducing the net present value of their lifetime spending in Rocha Department. Therefore, destination marketers should determine an optimal level of resource allocation and destination management activities that compare both present costs and discounted potential future income of the different target markets.

\section{Limitations and future work}

Since the domestic travel market accounts for almost three out of four arrivals to Rocha Department, and since Montevideo Metro Area accounts for half the population of Uruguay, the study covers an important part of Rocha's target markets. However, this study did not survey Brazilians, Argentinians, and other non-residents who visit the region. This limitation could be overcome by sampling tourists from abroad, using now only the 25 benefit statements after the classification performed. For this, the SVM model - the best classifier in this setting - would allow Rocha's destination marketers to assign a probability of cluster membership for each non-resident interviewed. Also, the age of respondents is slightly skewed towards younger respondents, although efforts were successfully made to include older respondents in the sample. More generally, these limitations could be overcome in a subsequent stage with an on-site data collection procedure such as self-administered questionnaires in selected locations of Rocha Department.

Regarding the classification problem, one future direction for this research would be to use different classifiers. In particular, methods that apply weights to various classifiers would be particularly suitable for the framework of this problem.

\section{References}

Akaike, H. (1981), "Likelihood of a model and information criteria", Journal of Econometrics, Vol. 16 No. 1, pp. 3-14.

Almeida, A.M.M., Correia, A. and Pimpão, A. (2014), "Segmentation by benefits sought: the case of rural tourism in Madeira", Current Issues in Tourism, Vol. 17 No. 9, pp. 813-831.

Breiman, L. (2001), "Random forests”, Machine Learning, Vol. 45 No. 1, pp. 5-32.

Breiman, L., Friedman, J.H., Olshen, R.A. and Stone, C.J. (1984), Classification and Regression Trees, Wadsworth and Brooks. Monterey, CA.

Brida, J.G., González, M.N. and Lanzilotta, B. (2017), “Análisis de los determinantes del turismo interno en Uruguay”, Revista de Estudios Regionales, Vol. 108.

Brida, J.G., Scuderi, R. and Seijas, M.N. (2014), "Segmenting cruise passengers visiting Uruguay: a factor-cluster analysis", International Journal of Tourism Research, Vol. 16 No. 3, pp. 209-222. 
Bourel, M. (2012), "Model aggregation methods and applications", Memoria de Trabajos de Difusion Cientifica y Técnica, Vol. 10, pp. 19-32.

Bourel, M. (2013), "Apprentissage statistique par aggregation de modèles”, $\mathrm{PhD}$ thesis, Université AixMarseille, Paris.

Collado, A.M., Navarro, D.M.C., Talaya, A.E. and Sánchez, E.D. (2007), "Segmentación de la demanda turística: un análisis aplicado a un destino de turismo cultural", Revista de Análisis Turístico, Vol. 4.

Devroye, L., Györfi, L. and Lugosi, G. (1997), “A probabilistic theory of pattern recognition”, corrected 2nd edition, Volume 31 of Applications of Mathematics, Springer, New York, NY.

Dolnicar, S. (2004), "Beyond 'commonsense segmentation': a systematics of segmentation approaches in tourism”, Journal of Travel Research, Vol. 42 No. 3, pp. 244-250.

Dolnicar, S. (2008), "Market segmentation in tourism", Tourism Management, Analysis, Behaviour and Strategy, Vol. 1, pp. 129-150.

Dutta, S., Bhattacharya, S. and Guin, K.K. (2017), "Segmentation and classification of indian domestic tourists: a tourism stakeholder perspective", Journal of Management and Training for Industries, Vol. 4 No. 1, p. 1.

Greene, W.H. (2012), Econometric Analysis, 71th ed., Stern School of Business, New York, NY University, New York, NY.

Hair, J.F., Black, W.C. and Babin, B.J. (2010), Multivariate Data Analysis, Vol. 7, Pearson Prentice Hall, Upper Saddle River, NJ.

Haley, R.I. (1968), "Benefit segmentation: a decision-oriented research tool", Journal of Marketing, Vol. 1, pp. 30-35.

Hastie, T., Tibshirani, R. and Friedman, J. (2008), "The elements of statistical learning; data mining", Inference and Prediction, Springer, New York, NY.

James, G., Witten, D., Hastie, T. and Tibshirani, R. (2013), An Introduction to Statistical Learning, Vol. 6: Springer, New York, NY.

Johns, N. and Gyimóthy, S. (2002), "Market segmentation and the prediction of tourist behavior: the case of Bornholm, Denmark", Journal of Travel Research, Vol. 40 No. 3, pp. 316-327.

Kotler, P. and Armstrong, G. (2010), Principles of Marketing, Pearson Education, London.

Kotler, P., Haidner, D.H. and Rein, I. (1993), Marketing Places: attracting Investment, Industry, and Tourism to Cities, States, and Nations, The Free Press, New York, NY.

Laesser, C. and Zehrer, A. (2012), "Tell me who you think you are and i tell you how you travel. Exploring the viability of market segmentation by means of travelers' stated personality: insights from a mature market (Switzerland)", Tourism Analysis, Vol. 17 No. 3, pp. 285-298.

Li, X.R., Meng, F., Uysal, M. and Mihalik, B. (2013), "Understanding China's long-haul outbound travel market: an overlapped segmentation approach”, Journal of Business Research, Vol. 66 No. 6, pp. 786-793.

Llambí, C. and Piñeyro, L. (2012), "Índice de nivel socioeconómico”, Revisión anual (2012), available at: www.ceismu.org/images/revision_inse_2012.pdf.

Loker, L.E. and Perdue, R.R. (1992), "A benefit-based segmentation of a nonresident summer travel market”, Journal of Travel Research, Vol. 31 No. 1, pp. 30-35.

López-Guzmán, T., Torres Naranjo, M., Pérez Gálvez, J.C. and Carvache Franco, W. (2017), "Segmentation and motivation of foreign tourists in world heritage sites: a case study, Quito (Ecuador)", Current Issues in Tourism, Vol. 1, pp. 1-20.

Mayer-Schönberger, V. and Cukier, K. (2013), Big Data: A Revolution That Will Transform How we Live, Work, and Think, Houghton Mifflin Harcourt. Boston. 
MINTUR (2016), “Anuario 2015”, Ministerio de Turismo de Uruguay.

MINTUR (2014a), “Anuario 2013”, Ministerio de Turismo de Uruguay.

MINTUR (2014b), "Bases de datos”, Ministerio de Turismo de Uruguay, available at: www.mintur.gub. uy/index.php/en/2014/itemlist/category/638-destinos

Neal, W.D. (2005), "Principles of market segmentation", American Marketing Assocation. MarketingPower.com, available at: www.marketingpower.com/content1006.php

Nelder, J.A. and Wedderburn, R.W.M. (1972), "Generalized linear models", Journal of the Royal Statistical Society, Series A, General, Vol. 135 No. 3, pp. 370-384.

Neuts, B., Romão, J., Nijkamp, P. and Shikida, A. (2016), "Market segmentation and their potential economic impacts in an ecotourism destination: an applied modelling study on Hokkaido", Tourism Economics, Vol. 22 No. 4, pp. 793-808.

Niefer, I.A. (2005), "Profile of visitors to the island of Superagüi, South Brazil", Tourism in Marine Environments, Vol. 1 No. 2, pp. 105-119.

Peter, J.P. and Donnelly, J.H. (2008), A Preface to Marketing Management, McGraw Hill Irwin. Homewood, IL.

Pike, S. (2012), Destination Marketing, Routledge. New York, NY.

Prayag, G. (2010), "Images as pull factors of a tourist destination: a factor-cluster segmentation analysis", Tourism Analysis, Vol. 15 No. 2, pp. 213-226.

Punzo, L. and Narbondo, M. (2009), Diagnóstico Participativo y Estrategia Competitiva Del Cluster de Turismo de Rocha, Montevideo. PACPYMES, available at: https://de.scribd.com/document/ 257416579/Rocha-PDF-Para-Web

R Core Team (2016), R: A Language and Environment for Statistical Computing, R Foundation for Statistical Computing, Vienna.

Rondan-Cataluña, F.J. and Rosa-Díaz, I.M. (2014), "Segmenting hotel clients by pricing variables and value for money", Current Issues in Tourism, Vol. 17 No. 1, pp. 60-71.

Sarigöllü, E. and Huang, R. (2005), "Benefits segmentation of visitors to Latin America", Journal of Travel Research, Vol. 43 No. 3, pp. 277-293.

Smith, W.R. (1956), "Product differentiation and market segmentation as alternative marketing strategies", Journal of Marketing, Vol. 1, pp. 3-8.

Sue, V.M. and Ritter, L.A. (2012), Conducting Online Surveys, Sage. Thousand Oaks, CA.

Tan, A.Y. and Lo, A.S. (2008), "A benefit-based approach to market segmentation: a case study of an American specialty coffeehouse chain in Hong Kong", Journal of Hospitality and Tourism Research, Vol. 32 No. 3, pp. 342-362.

Tkaczynski, A. (2009), “Destination segmentation: a recommended two-step approach”, Doctoral thesis, available at: http://eprints.usq.edu.au/6255/2/Tkaczynski_2009_whole.pdf

Tkaczynski, A., Rundle-Thiele, S. and Beaumont, N. (2010), "Destination segmentation: a recommended Two-Step approach”, Journal of Travel Research, Vol. 49 No. 2, pp. 139-152.

Tynan, A.C. and Drayton, J. (1987), "Market segmentation”, Journal of Marketing Management, Vol. 2 No. 3, pp. 301-335.

Valdez, R. Tamagni, L. and Zanfardini, M. (2008), "Hierarchical travel-market segmentation based on travel expenses", The case of San Martin de los andes, Revista Turismo and Desenvolvimento, Patagonia, available at: https:/proa.ua.pt/index.php/rtd/article/download/13581/9113

Vapnik, V.N. (1995), The Nature of Statistical Learning Theory, Springer-Verlag, New York, NY.

Weaver, D.B. (2006), Sustainable Tourism: Theory and Practice, Routledge. London.

\section{Further reading}

Bieger, T. and Laesser, C. (2002), "Market segmentation by motivation: the case of Switzerland", Journal of Travel Research, Vol. 41 No. 1, pp. 68-76. 
Cavalleri, F. and Larruina, K. (2010), Informe de Relevamiento. Temporada 2009-2010, Intendencia Municipal de Rocha, Rocha.

Crompton, J.L. (1979), "Motivations for pleasure vacation", Annals of Tourism Research, Vol. 6 No. 4, pp. $408-424$.

Dolnicar, S. and Leisch, F. (2004), Geographical or behavioural segmentation? The pros and cons for destination marketing. University of Wollongong Research, available at: http://ro.uow.edu.au/ cgi/viewcontent.cgi?article $=1255 \&$ context $=$ commpapers

Grupo Radar (2016), “El perfil del Internauta Uruguayo 2016”, available at: www.gruporadar.com.uy/ 01/wp-content/uploads/2016/11/El-Perfil-del-Internauta-Uruguayo-2016-Resumen-Ejecutivo.pdf

Stabler, M.J., Papatheodorou, A. and Sinclair, M.T. (2009), The Economics of Tourism, Routledge. London.

\begin{abstract}
About the authors
Gonzalo Perera has a $\mathrm{PhD}$ in mathematics from the Universidad de la República, Uruguay. His areas of specialization are statistics and probability. His main lines of research are non-parametric statistics, statistical processes, environmental statistics and data network statistical analysis. He is currently serving as the Dean of the Centro Universitario Regional Este, CURE, Uruguay.

Martin Sprechmann is a $\mathrm{PhD}$ Student of Tourism at the Universidad de Sevilla, Spain, and is currently a Research Assistant at the Facultad de Ciencias Económicas y de Administración, Universidad de la República, Uruguay. Most of the work for this study was done in a former position as a Research Assistant at the Centro Universitario Regional Este, Universidad de la República, Uruguay. Martin Sprechmann is the corresponding author and can be contacted at: msprechmann@ gmail.com

Mathias Bourel has a PhD in mathematics and statistics from Université Aix-Marseille, France. He is currently an Assistant Professor at the Universidad de la República, Uruguay. He works mainly in machine learning in the domain of ensemble methods for multiclass classification and density estimation, and its applications.
\end{abstract}




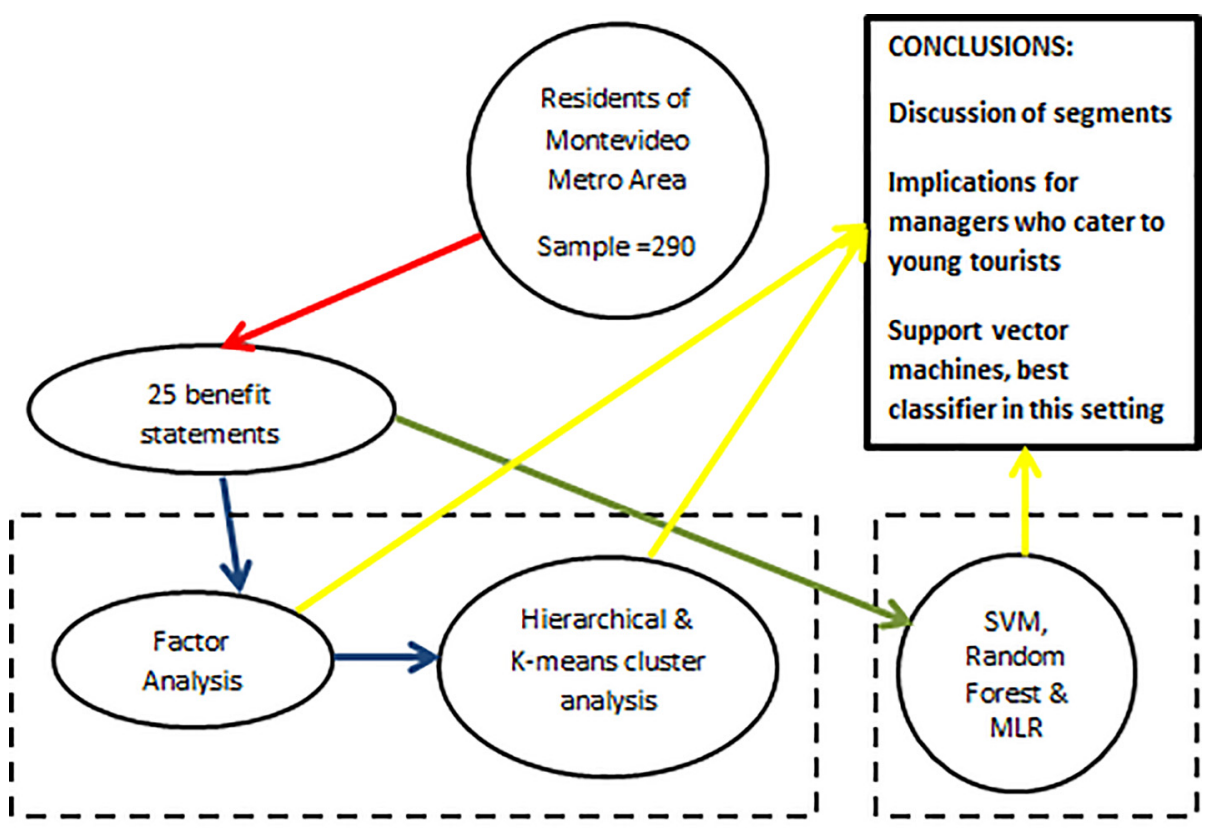

Figure A1 . Graphical abstract 
Statements related to nature

Statement $1 \quad$ Sightseeing

206

Statement 2 Visiting natural areas

\section{Statement 3}

Birdwatching

Statements related to socializing and nightlife

Statement $4 \quad$ Dance/bar

Statement 5 Dining/Restaurant

Statement $6 \quad$ Carnival

Statement $7 \quad$ Events

Statements related to outdoor activities

Statement $8 \quad$ To go to the beach

Statement 9 To walk on the beach

Statement $10 \quad$ General sports

Statement 11 To surf

Statement 12 To go fishing

Statement 13 To visit historic sites and

lighthouses

Statement 14 To go camping

Statements related to relaxing

Statement $15 \quad$ To rest and relax

Statement $16 \quad$ To see something different

Statement 17 To escape from everyday life

Statements related with the placés atmosphere

Statement 18 Rochás atmosphere

Statement 19 The friendly locals

Statement $20 \quad$ Safety place

Statement 21 It is a family oriented destination

Statement $22 \quad$ It is a friends oriented destination

Table AI.

Benefits sought

Statement 23

It is a quiet place

Statement $24 \quad$ Active atmosphere

Other statements

Statement 25 To go shopping
Frequently asked in different studies. See for example: Tkaczynski (2009)

Adapted from a local study by Cavalleri and Larruina (2010)

Asked by Sarigöllü and Huang (2005)

Asked by Sarigöllü and Huang (2005)

Own development in accordance to Rochás characteristics.

Asked by Sarigöllü and Huang (2005)

Asked by Sarigöllü and Huang (2005) and

Cavalleri and Larruina (2010)

Own development in accordance to Rochás

characteristics.

Asked by Sarigöllü and Huang (2005)

Asked by Sarigöllü and Huang (2005)

Asked by Sarigöllü and Huang (2005) and

Tkaczynski (2009)

Asked by Cavalleri and Larruina (2010)

Asked by Tkaczynski (2009)

Asked by Tkaczynski (2009)

Asked by Tkaczynski (2009)

Asked by Tkaczynski (2009)

Own development in accordance to Rochás characteristics.

Asked by Tkaczynski (2009) and Cavalleri and Larruina (2010)

Asked by Cavalleri and Larruina (2010)

Asked by Tkaczynski (2009)

Adaptation of Statement 21

Own development in accordance to Rochás

characteristics.

Own development in accordance to Rochás characteristics.

Own development in accordance to Rochás characteristics 